\title{
LOS INDÍGENAS DE LA AMAZONIA Y LOS INSECTOS. UNA VISIÓN COMPARADA ENTRE PUEBLOS SEDENTARIOS Y NÓMADAS DEL ALTO RÍO NEGRO - VAUPÉS
}

\author{
THE INDIGENOUS PEOPLE OF THE AMAZON AND INSECTS. A \\ COMPARATIVE VISION BETWEEN SEDENTARY VILLAGES AND NOMADS OF \\ THE ALTO RÍO NEGRO - VAUPÉS
}

\author{
Gabriel Cabrera Becerra ${ }^{1}$
}

\begin{abstract}
El consumo de insectos o entomofagia está ampliamente extendido en el mundo. En la región del Alto Río Negro - Vaupés frontera en la Amazonia de Colombia y Brasil los pueblos indígenas sedentarios y de tradición nómada incorporan un número importante de insectos en sus dietas. Si bien este hecho se menciona en la literatura, la mayoría de los contenidos aluden a la ingesta dejando de lado las asociaciones simbólicas de la práctica y no consideran condiciones particulares de la adaptación de estos pueblos. Este estudio traza una visión comparada del uso y simbología relacionada con los insectos para dos grupos de población cuya adaptación es diferente pero se viven interactuando en la misma área cultural.
\end{abstract}

Palabras claves: Amazonia, entomofagia, insectos, noroeste amazónico, abejas, hormigas, Alto Río Negro - Vaupés.

Insect consumption or entomophagy is widespread throughout the world. In the Alto Río Negro-Vaupés border region of the Colombian and Brazilian Amazon region, sedentary and nomadic indigenous peoples include a significant number of insects in their diets. Although this fact has been mentioned in the literature, most of the contents refer merely to intake, leaving aside the symbolic associations of this practice and disregarding the particular conditions for the adaptation of these peoples. This study draws a comparative view of the use and symbology related to insects of two population groups, which hold differences in adaptation terms but live in interaction with each other in the same cultural area.

Key words: Amazon basin, entomophagy, insects, Northwest Amazon, bees, ants, Alto Río Negro - Vaupés.

El consumo de insectos como alimento o entomofagia es una práctica ampliamente extendida en el mundo. La FAO estima que cerca de dos mil millones de personas principalmente en África, Asia y América Latina incluyen en sus dietas este alimento y que son cerca de 1.900 especies de insectos las que se comen, siendo aprovechados en su orden: los escarabajos (coleópteros) (31\%), las orugas (lepidópteros) (18\%) y las abejas, avispas y hormigas (himenópteros) (14\%), les siguen los saltamontes, las langostas y los grillos (ortópteros) (13\%), las cigarras, los fulgoromorfos y saltahojas, las cochinillas y las chinches (hemípteros) $(10 \%)$, las termitas (isópteros) (3\%), las libélulas (odonatos) (3\%), las moscas (dípteros) (2\%) y otros órdenes (5\%) (FAO 2013:xiii).
Pero el universo de los insectos no solo es enorme sino que ellos están en casi todos los ambientes; y se considera que existen 1.900 especies de insectos comestibles, la mayoría de ellos en las zonas tropicales (FAO 2013:1). Hace unos años se mencionaba que si bien había cerca de un millón de especies de insectos descritas, esta cifra sería baja pues se estima que hay cerca de 5.000 .000 de insectos en todo el mundo (Grimaldi y Engel 2005). En particular para las zonas tropicales, los insectos juegan un papel importante en la estructura y dinámica del ambiente: termitas, hormigas, abejas y avispas son una fracción importante de la biomasa y hacen parte de innumerables redes tróficas y ciclos (Jaison 1983, citado en Fernández 1999:31). En particular para la amazonia se estima que 428

\footnotetext{
${ }^{1}$ Universidad Nacional de Colombia, Departamento de Historia, Medellín, Colombia. gcabrerabe@unal.edu.co
} 
especies se consumen como alimento en la región (FAO 2013:9).

Los insectos brindan servicios como el control biológico, la descomposición de residuos orgánicos $\mathrm{y}$ en el caso de las abejas es bien conocido su papel polinizador; y diversos estudios señalan que hay una gran amenaza derivada de la contaminación, la destrucción o fragmentación de hábitats, la tala indiscriminada o la explotación no sustentable (Nates-Parra 1999:52). En el caso de Brasil un estudio puntualiza que la proximidad de cultivos extensos de soja, algodón, naranja y tomate no solo afectan a los meliponicultores sino a las colonias naturales en bosques próximos, al igual que el trabajo de leñadores que buscan arboles viejos en el bosque (con mayor ocurrencia de cavidades) destruyendo las potenciales casas de nuevos enjambres (Kerr 1997; Kerr et al. 2001).

Igualmente los insectos tienen un bajo nivel de riesgo en la transmisión de enfermedades a diferencia de otras especies de mayor tamaño como aves y reses, su recolección tiene costos bajos y son materia complementaria en la elaboración de concentrados para acuicultura. Empero no todos se emplean como alimento; pues los diversos pueblos aprovechan este recurso dependiendo de su forma de vida y las condiciones ambientales, asociando a su uso o consumo diversas valoraciones o asociaciones simbólicas. El propósito de este texto es brindar una lectura comparada del uso de insectos en el Vaupés, una región de la Amazonia colombo-brasileña.

Este artículo se ocupa de la relación entre los pueblos indígenas del área cultural del Vaupés con los insectos. Esta zona es reconocida como un complejo cultural en el que coexisten básicamente dos conjuntos de pueblos: grupos ribereño-sedentarios de horticultores-pescadores pertenecientes a las familias lingüísticas tucano oriental, arawak y carib, y grupos de tradición nómada de cazadores anteriormente conocidos como makú. En el primer grupo hay 19 pueblos tucano oriental, seis arawak y un carib. En el segundo grupo de los makú son seis pueblos. En la Figura 1 se aprecia su ubicación y en la Tabla 1 se discriminan los principales rasgos culturales de los dos conjuntos.

Aunque desde mediados del siglo XX la oferta y dispersión de proteína animal en la amazonia fue tema de discusión, en los años ochenta la polémica fue álgida. Se destacó el lugar de los tabús culturales por la danta y el venado como explicación de no consumo de las presas de mayor porte (Ross 1978), se enfatizó la escasez y dispersión de la proteína animal (Gross 1982a, 1982b), se recordó el amplio espectro de proteína contenida en vegetales e insectos (Beckerman 1982) y se puntualizó que dantas y cerdos eran más comunes de lo que se creía en la zona montañosa subandina, pero que sus tabús se explican en términos microecológicos y no son generales para la Amazonia (Vickers 1983). Es decir que el espectro de los alimentos no solo es grande, sino que factores culturales y ambientales tienen un peso en cómo se aprovechan los recursos o fuentes proteicas. Los insectos cobraron importancia y entonces se contó con los primeros estudios sobre su trascendencia para la zona de este estudio que detallamos adelante (Dufour 1987; Milton 1984).

Los registros sobre los insectos conocidos que corresponden a los pueblos de habla Tucano oriental provienen de diversas fuentes: sobre los makuna (Arhem 1981; Arhem et al. 2005; Cayón 2002, 2013), desana y tucano (Ramírez 2001; Reichel-Dolmatoff 1968,1996,1997), taiwano (Correa 1996), tatuyo (Dufour 1987), bara y tuyuka (Osorno et al. 2014), barasana (Hugh-Jones 2013); sobre los pueblos de habla arawak como los yucuna (Hammen 1992; Ortiz 1995;) y baniwa (Ramírez 2001). En tanto que para los pueblos nómadas las informaciones sobre los nukak y juhup provienen de trabajos de campo directos (Cabrera y Nates 1999; Cabrera et al. 1999; Franky 2011), sobre los kakua (Silverwood-Cope 1990) y hupda (Milton 1984; Reid 1979).

Algunos datos sobre entomofagia en la amazonia refieren el consumo de insectos entre 39 grupos nativos sobre una revisión bibliográfica de 120 grupos, es decir tan solo en un 32,5\% de ellos se menciona esta práctica (Bahuchet 1993) y solo para uno, los matis de Brasil, se anota la total ausencia del consumo de insectos (Milton 1997). Los registros sin embargo brindan una dificultad, pues en muchas ocasiones solo se conoce el nombre nativo del insecto pero no su identificación científica. Entre los yanomami se mencionan 142 términos para insectos probablemente comidos pero no identificados (Finkers 1986). Otros autores refieren 56 especies consumidas en toda Suramérica (Dufour y Sander 2000), pero para el Ecuador se menciona un total de 82 especies (Onore 2004). Estudios más recientes señalan la existencia de más de 200 especies de insectos consumidas en la Amazonia, agregando que existen muchos más para 


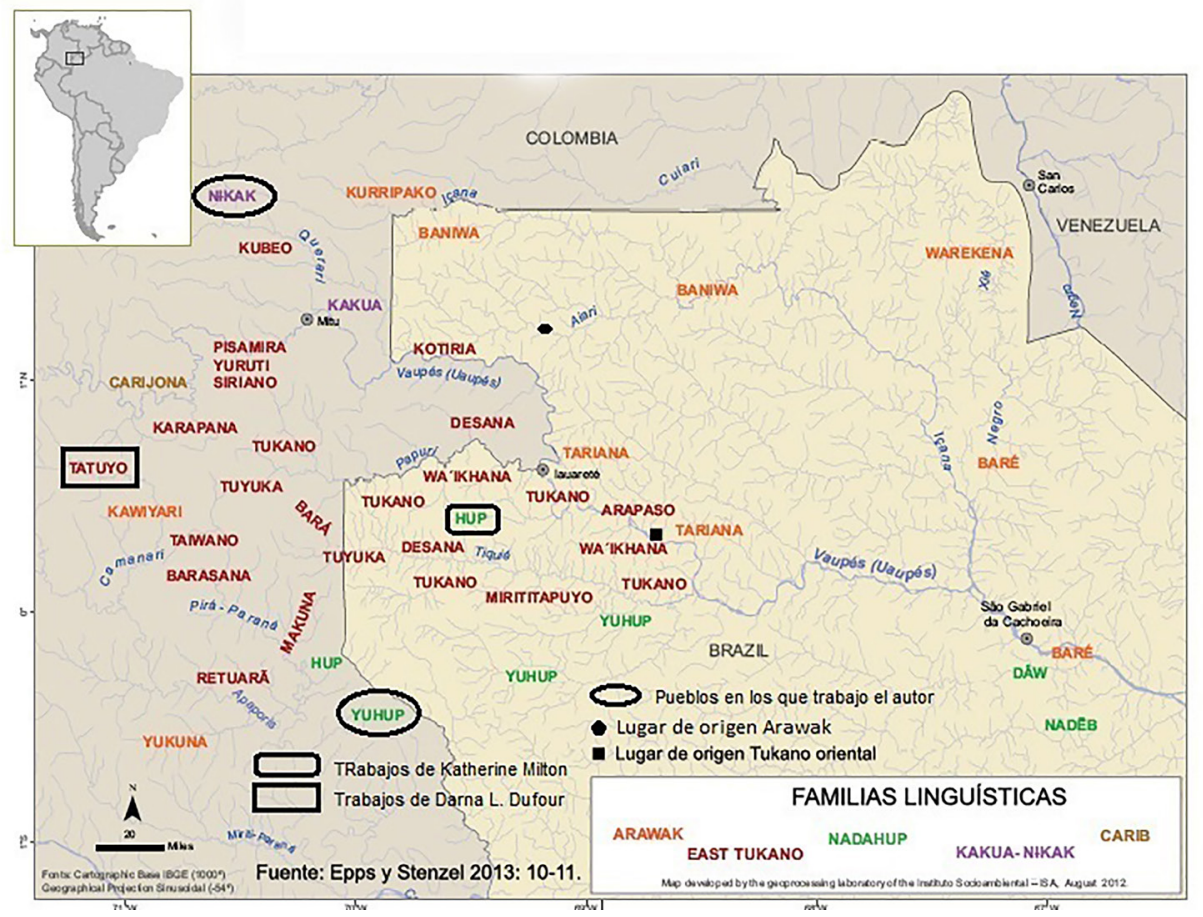

Figura 1. Alto Río Negro-Vaupés.

Alto Negro-Vaupés River.

Tabla 1. Adaptaciones culturales en el Alto Río Negro-Vaupés.

Cultural adaptations in the Alto Río Negro-Vaupés.

\begin{tabular}{|c|c|c|}
\hline Aspectos & Sedentarios & Nómadas \\
\hline Asentamiento & Disperso ribereño-sedentario & Nómadas en áreas interfluviales \\
\hline Base económica & Horticultura itinerante y pesca & Caza y recolección \\
\hline Alianza matrimonial & $\begin{array}{l}\text { Entre los tucano oriental exogamia lingüística [1], } \\
\text { excepto makuna [2] y cubeo [3]. } \\
\text { Entre los arawak exogamia entre fratrías localizadas } \\
\text { e identificadas con nombres propios asociadas a } \\
\text { territorios fluviales distintos y a un dialecto [4]. }\end{array}$ & Exogamia clánica [9] \\
\hline Filiación lingüística & $\begin{array}{l}\text { Tucano oriental - } 19 \text { etnias } \\
\text { Arawak - } 6 \text { etnias } \\
\text { Caribe - } 1 \text { etnia }\end{array}$ & $\begin{array}{l}\text { Anteriormente Makú-puinave hoy } 6 \text { etnias } \\
\text { Nadahup (nadeb, daw, hupda, juhup) [10] } \\
\text { o makú oriental y makú occidental (kakua, } \\
\text { nukak) [11] }\end{array}$ \\
\hline Lugar de origen & $\begin{array}{l}\text { tucano oriental - Cueva de Tocandira [5] } \\
\text { arawak - Raudal Hipana en el Río Aiary[6] }\end{array}$ & makú - zona en el bajo Río Negro \\
\hline $\begin{array}{l}\text { Organización social y } \\
\text { distribución espacial }\end{array}$ & Clanes jerárquicos mayores y menores & Clanes jerárquicos \\
\hline $\begin{array}{l}\text { Especialización } \\
\text { en elaboraciones } \\
\text { materiales }\end{array}$ & $\begin{array}{l}\text { baniwa - rayador [7] } \\
\text { wanano - Balay [7] } \\
\text { desana - Balay [8] } \\
\text { tucano - Bancos [8] }\end{array}$ & Cacería, veneno, cerbatanas, canastos [12] \\
\hline Vivienda & Maloca & Campamentos (tipitis) y malocas [12] \\
\hline
\end{tabular}

[1] Sorensen 1967, Jackson1983; [2] Arhem 1991; [3] Goldman 1968.; [4] Hill 1986:69; [5] Correa 1996:223; [6] Wright 1983:538; [7] Chernela 1993:111; [8] Reichel-Dolmatoff 1986; [9] Athias 2006:18; [10] Epps 2008:3-8; [11] Martins 2005; [12] Silverwood-Cope 1990; Reid 1979. 
los cuales solo se conoce la denominación étnica, pero se desconoce su identificación (Paoletti y Dufour 2000).

En cuanto a los usos y sus asociaciones simbólicas algunos ejemplos de la literatura ilustran en parte lo que aquí persigo exponer. Entre los hoti exoesqueletos quemados de avispas, hormigas, orugas hacen parte de las pinturas corporales que actúan "como armaduras que protegen a la persona contra seres potencialmente malevolentes o peligrosos" (Zent y Zent 2007:109). Los yanomami tienen un afrodisíaco llamado kumi, que:

se prepara cuando la larva de un cierto coleóptero se aloja en un bejuco, la madera exhala un fuerte perfume, y entonces ellos recogen los excrementos de dicha larva, madera mascada y digerida que se seca sobre el fuego y se reduce a polvo. Los hombres hacen respirar ese polvo por la fuerza a las mujeres, aplicándoles con firmeza la mano sobre la boca y la nariz (Lizot 2007:296).

Los piaroa creen que los animales de caza son atraídos por los hombres que aguantan mejor las pruebas de iniciación. "El poder asociado a la ponzoña de las hormigas, avispas y rayas es transferido al cuerpo y $a_{s}$ ' $c u a_{s} r u_{s} h u a_{s}$ (espíritu) del iniciado con las picaduras, dándole fuerza (ujuru) para pensar, hablar, trabajar, resistir enfermedades y relacionarse con los demás; en otras palabras, lo preparan para vivir plenamente" (Freire y Zent 2007:158).

\section{Los Pueblos Sedentarios y los Insectos en el Vaupés}

Al revisar la literatura etnográfica sobre los pueblos de la región del Vaupés se ratifica la apreciación relacionada con los nombres, pues los investigadores nominan los insectos de manera diferente. Entre los grupos tucano oriental (9 de 19) y arawak (2 de 6) el total relacionado de insectos es 147 distribuidos así: 51 hormigas $(34,6 \%)$, 18 abejas (12,2\%), 14 avispas (9,5\%), 14 larvas $(9,5 \%), 12$ escarabajos $(8,1 \%), 11$ termitas $(7,4 \%)$, siete gusanos $(4,7 \%)$, seis orugas $(4 \%)$, cuatro grillos $(2,7 \%)$, tres comejenes ( $2 \%)$, tres cucarrones $(2 \%)$, dos chicharras $(1,3 \%)$, una libélula $(0,6 \%)$, un tábano $(0,6 \%)$, un zancudo $(0,6 \%)$ e indeterminados seis (4\%). Si seguimos los criterios de los órdenes tendremos entonces: 83 himenópteros $(56,4 \%)$, 15 coleópteros $(10,2 \%), 11$ isópteros $(7,4 \%)$, seis lepidópteros $(4 \%)$, cuatro ortópteros $(2,7 \%)$, siete hemípteros $(4,7 \%)$ y un odonato $(0,6 \%)$.

La idea de que como parte de la biomasa amazónica la oferta de insectos bien puede aprovecharse no se corresponde con la práctica cultural de todos los pueblos del Vaupés. Específicamente un investigador recuerda "los barasana con quienes vivimos solo recolectaron miel dos veces en dos años y únicamente porque nosotros insistimos. Es como si el interés en la miel hubiese sido reemplazado por el interés en la cera de abejas" (Hugh-Jones 2013:215).

Un trabajo pionero sobre este tema en la zona fue adelantado entre los tatuyo en la aldea Yapú en las cabeceras del Río Papurí por Darna L. Dufour, entre noviembre de 1976 y abril de 1978. La existencia de este asentamiento fue impulsada por los misioneros javieres en los años sesenta y para 1977 había reunido unas 140 personas que antes vivían en pequeños grupos a lo largo del caño Yapú (Dufour 1984-1985:240). En la Figura 1 se puede apreciar el lugar de sus trabajos. El estudio señala que durante los meses de mayo a junio el consumo de insectos suministra un $12 \%$ de la dieta masculina y un 26\% de la femenina (Dufour 1987, citado en Paoletti y Dufour 2000). El inventario incluido en la Tabla 2 relaciona el consumo de 16 especies que incluyen hormigas, termitas, orugas, avispas, abejas y gusanos.

En el estudio sobre los tatuyo se relaciona un total de 14 especies de insectos, señalando que su valor nutricional es alto pues según la autora estos aportaban entre 425-661 kcal por 100 gr. El valor energético de las hormigas hembras y larvas de mojojoy era tan alto como el contenido graso (Dufour 1987). Los valores de hormigas, termitas y escarabajos que se pueden leer en la Tabla 3 se asemejan en términos de proteínas como equivalentes al pescado seco, cuyos valores son 312 (energía), 43,4 (proteínas), 7,0 (grasa). La composición de los insectos consumidos es similar a la de otro tipo de comida animal, y aunque algunos tienen un valor más bajo en cantidad y calidad de proteína su composición de aminoácidos es complementaria a la dieta (Sotomayor-Tribín et al. 1998:130). Para otras valoraciones similares véase FAO 2013. 
Tabla 2. Consumo de insectos entre los indígenas tucano, en una aldea de 100 personas, Vaupés, Colombia. Insect consumption among the Tucano indigenous inhabitants, in a village of 100 inhabitants, Vaupés, Colombia.

\begin{tabular}{lcccc}
\hline \multicolumn{1}{c}{ Insectos } & Peso (g) & $\mathrm{kg} \mathrm{y} \%$ & $\%$ & $\begin{array}{c}\text { Hojas }+ \\
\text { hojarasca }\end{array}$ \\
\hline Atta soldados y reinas (3 especies) & $0,1-0,9$ & 100 & 29,3 \\
\hline Syntermes soldados & 0,28 & 133 & 3996,5 & $96,5 \%$ \\
\hline Caterpillars (5 especies) & $1,46-3,06$ & 96 & 28,15 & 0,6 \\
\hline Vespidae larva y pupa (3 especies) & $0,2-0,4$ & 2 & 1,5 & 0,44 \\
\hline Meliponinae larva y pupa (1 especie) & 0,1 & 6 & 1,7 \\
\hline Rhyncophorus palmarum larva & $8-12$ & 2,5 & \\
\hline $\begin{array}{l}\text { Larvas de escarabajo criados en madera muerta (3 } \\
\text { especies: Scarabaeidae, Buprestidae, Cerambycidae, }\end{array}$ & 2,8 & 2 & \\
Passalidae* & & & \\
\hline
\end{tabular}

Fuentes: Paoletti y Dufour 2000*; FAO 2013.

Con certeza todos estos pueblos tienen más o menos elaborados sistemas de clasificación de los seres vivos de la naturaleza. En el área vecina del Río Caquetá un trabajo exhaustivo detalla este tópico para los insectos (Jara 1996). Para la zona de este estudio un ejemplo se encuentra entre los Tucano, que clasifican los animales entre comestibles y no comestibles. Entre los primeros las hormigas hacen parte de las bestias que pertenecen a la tierra, en tanto que las termitas, avispas, abejas y cigarras hacen parte de las bestias que pertenecen a los árboles (Reichel-Dolmatoff 1997:35).

Si bien el mayor uso entre los tucano oriental y arawak es el alimenticio, algunos insectos en particular, por su crecimiento, marcan algunos momentos claramente identificados para estos pueblos. Entre los makuna su ciclo anual incluye el kao oka rodo (época de hormiga arriera) en julio o

Tabla 3. Valor nutricional de los insectos comidos en la Amazonia.

Nutritional value of insects eaten in the Amazon.

\begin{tabular}{ccccc}
\hline Alimento & Nombre científico & Energía & Proteínas (g) & Grasa (g) \\
\hline Hormiga (hembra) & Atta sexdens & 628 & 39,7 & 34,7 \\
\hline Hormiga (hembra) & Atta cephalotes & 580 & 48,1 & 25,8 \\
\hline Oruga & Syntermes sp. & 467 & 58.9 & 4,9 \\
\hline Larvas de palmas secas & Rhynchophorus sp. & 661 & 24,3 & 55,0 \\
\hline $\begin{array}{c}\text { Orugas secas (varias } \\
\text { especies) }\end{array}$ & & 425 & 52,6 & 15,4 \\
\hline
\end{tabular}

Fuente: Dufour 1987.

el ia küma (verano de gusano) en septiembre, donde "hay una gran cantidad de gusanos comestibles (Cayón 2002:94). Los yucuna en los meses de septiembre y octubre reconocen el tiempo de gusanos y chicharras (Hammen 1992:122). Entre los tucano otros insectos, como termitas y orugas, son estacionalmente colectados entre febrero y marzo cuando son ahumados. Las orugas son también comidas en la estación seca, tostadas con casabe (Reichel-Dolmatoff 1996:189). Así mismo, un grillo arborícola no identificado llamado bárisero aparece en grandes cantidades en palmas o cerca de malocas y se dice que está correlacionado a ciertas fases de la luna y durante su menguante se recogen y se comen tostados (Reichel-Dolmatoff 1997:304).

Dentro del inventario tucano y arawak es claro que dos especies son ampliamente usadas como 
alimento. Las hormigas arrieras del género Atta y las larvas de coleóptero conocidas con los nombres de suri, chontacuro, mayón, mukint (Ecuador), gualpa, mojojoy (Colombia) y gusano de palma (Venezuela), donde son también de los insectos más consumidos (Cartay 2018:152-153). La captura de hormigas modifica la pauta rutinaria del asentamiento, como refiere una investigadora al recordar que: "En cuanto a las salidas nocturnas, los indígenas evitan visitar el monte, pero la recolección de las hormigas es un hecho especial para los yucuna, quienes por lo demás poseen un profundo conocimiento sobre esta especie, el cual puede estar relacionado con el nombre del "sib" sobreviviente de los yucuna: los kamejeya, término relacionado con la cacería, por una parte, pero a la vez el nombre con que se reconoce a una especie de hormiga arriera de color negro (Hammen 1992:117). Entre los grupos tucano las hormigas comestibles son alimentos masculinos con atributos afrodisiacos (Reichel-Dolmatoff 1997:189). En otros momentos existe un consumo específico de insectos, como se refiere entre los barasana, que comen las termitas ôhera en el ritual de paso masculino (Hugh-Jones 2013:282).

Las larvas de mojojoy se crían en troncos de distintas especies de palmas como el milpeso (Oenocarpus bataua) y el moriche (Mauritia flexuosa) siendo la más grande la de la primera especie. Para su desarrollo los indígenas tumban unos cuatro meses antes las palmas y hacen un hueco para que el insecto adulto ponga sus huevos. Los yucuna en particular refieren que el "pico del adulto destruye los dientes del consumidor", por lo cual solo puede ser consumido por los viejos, que al no tener dientes no corren el riesgo de perderlos, la asociación es clara pues alude al acto de taladrar que es lo que el insecto hace a la palma; en tanto que las larvas que se consumen crudas, ahumadas $\mathrm{o}$ asadas son objeto de intercambio entre parejas o de atención especial entre ellas (Ortiz 1995:76, 79). Hay consenso entre los investigadores que esta forma deliberada de obtener estos insectos es parte del espectro de manejo de los recursos entre los pueblos amazónicos, llegando a nombrarse por algunos como una cierta forma de cultivo (Balick 1986:17; Dufour 1987:385). Entre los tucano estas larvas son consideradas "una delicia afrodisiaca" (Reichel-Dolmatoff 1996:189).

En algunos casos los insectos se usan como ingredientes en ciertas preparaciones alimenticias.
Los yucuna a veces agregan hormigas en la preparación del tucupí (Hammen 1992:224). Igualmente, son objeto de intercambio, como entre los wanano entre quienes la captura de las reinas de Atta sexdens se hace en su periodo de vuelo nupcial y se intercambian con grupos afines (Chernela 1996:111), o los gusanos bahpáru que los Tucano recogen y ahúman e intercambian en los rituales a cambio de carne cazada ahumada con los desana (Reichel-Dolmatoff 1997:59). Un valor más asociado a los insectos entre los indígenas es su carácter patógeno, como hormigas, avispas, termitas y otros insectos que pueden infligir dolorosas mordeduras o picaduras (ReichelDolmatoff 1997:166).

Entre los insectos las abejas y en particular su miel es aprovechada por algunos pueblos, pero su cera tiene un valor especial en el universo simbólico de algunos de ellos. Los barasana colocan la cera de la abeja werea en un recipiente considerado como el hígado de la anaconda palo de yuca, al que igualmente se le compara con los niños dentro del útero, es decir es un símbolo esencialmente femenino propiedad de Romi Kumu, la mujer chamán. La quema de la cera produce un olor penetrante y aromático que los indígenas asocian a la fragancia vaginal y que como objeto se opone y complementa las trompetas $\mathrm{He}$, el símbolo masculino identificado con anacondas ancestrales masculinas (Hugh-Jones 2013:219-228). Antes de quemar la cera el chamán sopla conjuros sobre ella $\mathrm{y}$ tras quemarla en un recipiente la carga y esparce el humo hacia los cuatro puntos cardinales usando un abanico tejido, consiguiendo así la wanose (curación de protección) que aleja la nyase rohagu (enfermedad aguda y crónica); así mismo, la miel no solo se quema en los rituales de iniciación masculina o $\mathrm{He}$, sino también cuando una mujer vuelve a la maloca después de dar a luz, cuando una niña tiene su primera menstruación, cuando alguien fallece para asegurar que el wãti (espíritu) salga del cuerpo del difunto, durante los eclipses solares y lunares cuando la luna se vuelve roja y muere, o durante una epidemia para alejar la enfermedad grave se hace inhalar humo de cera y tomar agua en la que se gotea cera derretida al enfermo, también se quema cera después de la mordedura de una serpiente, después de quemar los árboles derribados en la chagra para enfriarlos, en las chagras para alejar plagas (Hugh-Jones 2013:241-242). La 
Figura 2 muestra una ilustración del recipiente que contiene la cera, su pintura y significados.

Las asociaciones con la fertilidad son un tema recurrente entre los Desana, donde cierta hormiga representa un principio masculino y fálico por su olor y picadura, y su secreción se compara al semen; cierto comején y al mojojoy también se les compara al semen, aunque el cuerpo blando del último simboliza impotencia. Cierta abeja es animal solar, productor de miel, es decir semen, y representa la recolección una actividad masculina (Reichel-Dolmatoff 1968:129-130). Entre la mayoría de pueblos de filiación lingüística tucano oriental las formas hexagonales como la de los panales de abejas y avispas están asociadas a fuerzas transformadoras, analogía que se extiende a otros elementos y expresan orden (ReichelDolmatoff 1997).

Entre los makuna sucede otro tanto. $\mathrm{Al}$ momento del parto se hace curación quemando werea (cera de abejas), que limpia el sitio y protege al bebe del rapto de waso maku un ser no humano que muestra inclinación por los recién nacidos, mujeres parturientas y menstruantes para convertirlas en parafernalia ritual de sus malocas (Cayón 2013:287). Cada dueño de maloca tiene un bloque de esa cera, el cual se raspa en finas lascas que se queman en determinados momentos de las curaciones; el dueño de la maloca toma un abanico hecho de plumas de pava y va recorriendo el espacio central de la maloca dispersando el humo. Ese humo tiene un olor muy agradable que produce una sensación

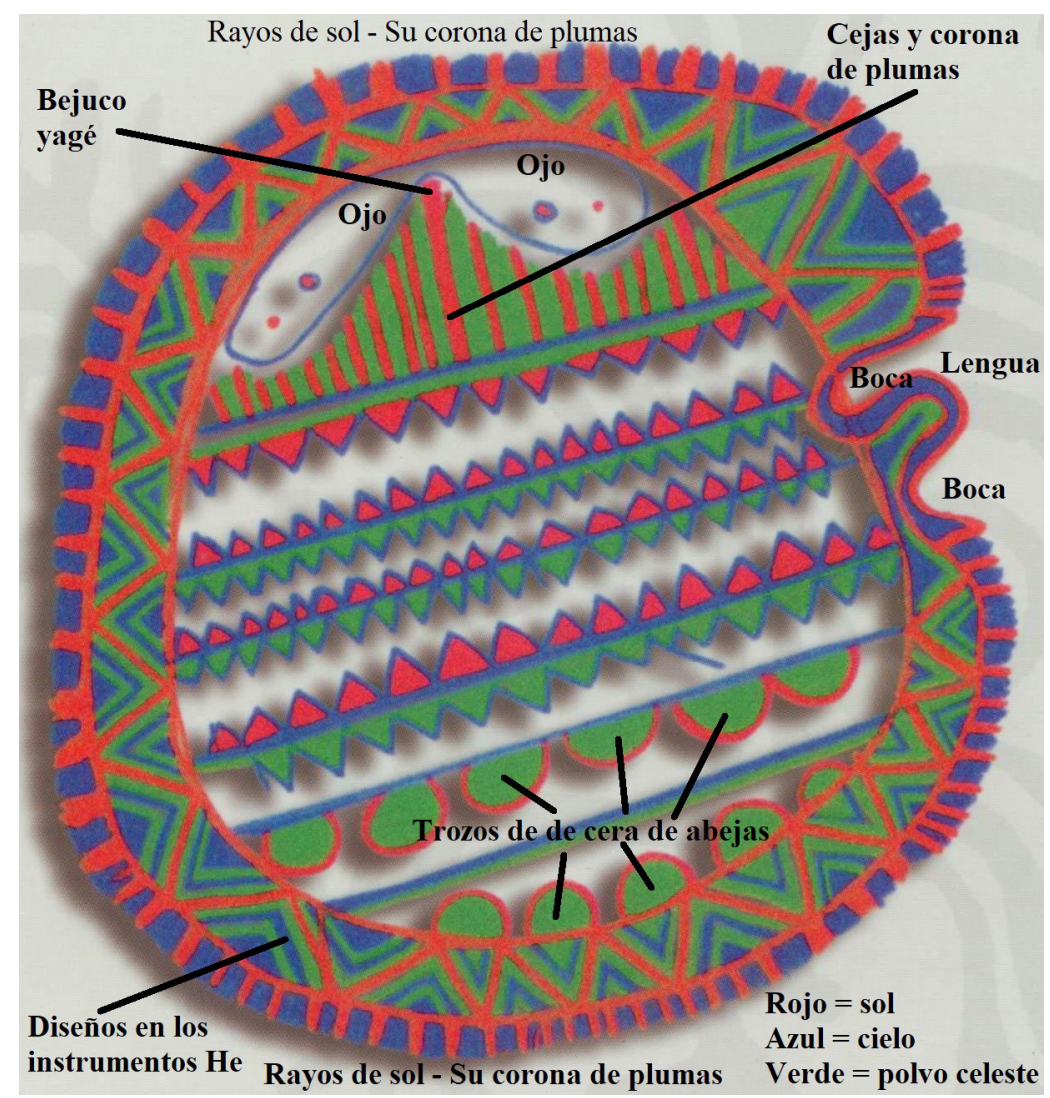

Figura 2. Cuya de cera de abeja (Hugh-Jones 2013:218).

Beeswax container (Hugh-Jones 2013:218). 
muy reconfortante y estimulante. Werea es un tipo de incienso y uno de los elementos rituales más importantes para los makuna. En la curación se deposita dentro de una cuya con coca, y el chamán sopla sobre éste y por momentos le da vueltas dentro de la cuya, untándolo de coca. Hay un momento en que el chamán entrega la cuya al dueño de la casa, quien invita a los presentes a acercarse a la cuya, y entonces cada uno unta su dedo índice con coca y lo chupa (Cayón 2013:356).

Entre los curripaco las epidemias se entienden como una interrupción total de las relaciones entre los ancestros míticos y los descendientes humanos, situación que puede matar a toda una comunidad. En estas ocasiones, "los dueños del canto deben recolectar la miel rojiza de la especie de abeja más poderosa, llamada eenui (Trigona sp.) y fumigar la comunidad con humo generado por la quema del material resinoso de la colmena. Toda la comunidad participa en el acto ritual de beber la miel de eenui y se suspenden las relaciones con otras comunidades hasta que la enfermedad y la muerte cesan" (Hill y Oliver 2007:28). Otro uso recurrente de los insectos es como carnada para pescar: los yucuna usan grillos (Hammen 1992:262), los tucano usan hormigas o saltamontes (Ramírez 2001:158). La cera también se emplea para algunas elaboraciones materiales, como las cerbatanas de los tucano en cuyo extremo se fijan como guía dientes de paca con breo o cera de abejas (Ramírez 2001:155).

\section{Los Pueblos de Tradición Nómada y los Insectos}

Los pueblos de tradición nómada en el área de este estudio son seis: nukak, kakua o bara, juhup, hupda, daw y nadeb. Los dos primeros tienen su territorio en Colombia y los dos últimos en Brasil, los juhup y hupda viven en ambos países (Cabrera 2010:24). Las informaciones en la literatura etnográfica refieren que los kakua o bara consideran que los insectos son animales sin sangre y pueden comerse crudos; hombres y mujeres aprovechan 24 tipos de insectos comestibles entre ellos 12 hormigas, dos termitas, dos larvas de escarabajo $\mathrm{y}$ un abejorro, siendo un recurso complementario durante el periodo menstrual cuando es peligroso comer caza o peces (Silverwood-Cope 1990). Con relación a la miel, los kakua conocen ocho especies de abejas que colectan luego identificando su ubicación por el sonido, y luego usan antorchas de hojas secas para espantar los insectos y finalmente talan el árbol; el consumo se hace in situ y en el campamento, y los jóvenes reúnen la cera para hacer la boquilla de sus flautas (Silverwood-Cope 1990:52). Los juhup aprovechan dos especies de abejas, una de hormigas y dos de coleópteros (Mahecha et al. 2002:159). Los hupda de Brasil utilizan un número indeterminado de larvas, orugas y termitas (Reid 1979). Los nadeb manejan al menos una especie de abeja para miel (Münzel 19691972). Tanto los hupda como los kakua estaban ya semisedentarizados a comienzos de los años setenta y solo hacían esporádicas incursiones en el bosque que tenían una duración de tres a cuatro semanas. En cuanto a los juhup, para comienzos de los años noventa ya vivían la misma circunstancia.

De manera similar, con relación a los pueblos makú y los insectos existe un trabajo pionero realizado por Katherine Milton entre los hupda del Río Tiquié, en donde entre junio y octubre de 1981 visitó siete comunidades, incluidas Nova Fundação y São Joaquim, creadas por impulso de los misioneros salesianos, y cinco asentamientos tradicionales, uno de los cuales fue visitado en dos ocasiones (Milton 1984:13). En la Figura 1 se puede apreciar el lugar de sus trabajos. La pesquisa señala que los grupos nómadas de la región recogen insectos durante la estación lluviosa cuando la caza y pesca disminuyen; y que su patrón contrasta con el de los sedentarios tucano, ya que los nómadas makú, que viven en grupos pequeños, son carnívoros y priorizan la caza en la consecución de recursos e intercambian los excedentes de carne con los tucano que les suministran alimentos cultivados (Milton 1984:19).

En particular, los datos sobre los nukak y los juhup provienen de observaciones directas. En ambos trabajos se empleó un instrumento de registro diseñado previamente que hace plenamente comparable las informaciones, que consideraba como variables: fecha, nombre vernáculo, descripción de la especie, consumo (in situ o en campamento en gr), expedición (específica u ocasional), tiempo de la actividad (minutos), lugar (msm y coordenadas GPS), participantes, transporte, repartición, preparación o consumo (para insectos cocido, crudo, asado, otro) para miel (pura o aguamiel), técnical herramienta para los insectos (hacha, machete, palo, manual, otra), técnica/herramienta para la miel (tala del tronco, derribada del panal, andamio, abrir tronco, antorcha, ascenso por el tronco), materias primas o usos y observaciones adicionales. 
Los nukak eran absolutamente nómadas y cambiaban su lugar de residencia unas 68 veces en el año, con una permanencia promedio de 5,3 días y una presencia mínima registrada de una noche y una máxima de 28 noches (Cabrera 1999:148; 2005:64). Los registros entre los nukak fueron recogidos en trabajos que involucraron 797 días en su territorio tradicional y de los cuales convivimos 644 días con ellos, los datos cubren 10 de los 13 grupos locales conocidos (Cabrera et al. 1999:18). Los trabajos de campo entre los juhup cubren ocho meses y pertenecen a la comunidad de La Libertad en la zona del bajo Río Apaporis.

Los registros de los nukak demuestran que ellos emplean 43 especies de abejas productoras de miel (20 identificadas), 14 de avispas y 16 orugas (Mahecha et al. 2000:159; Nates y Cabrera 1999:62), uno de cuyos ejemplos se aprecia en la Figura 3. Un hecho particular de los nukak es que no se observó el consumo de hormigas ni termitas (Sotomayor -Tribín et al. 1998:130). La Tabla 4 sintetiza el uso de insectos por cinco de los pueblos nómadas, para los daw no hay datos. De esta se colige que los pueblos de tradición nómada emplean un total de 116 insectos, distribuidos así: Himenópteros $(73,2 \%)$, Lepidópteros $(14,6 \%)$ Isópteros $(2,5 \%)$, larvas de coleópteros $(4,3 \%)$.

\section{Las Abejas y los Nukak}

Para las 20 abejas identificadas entre los nukak se cuenta con información adicional sobre

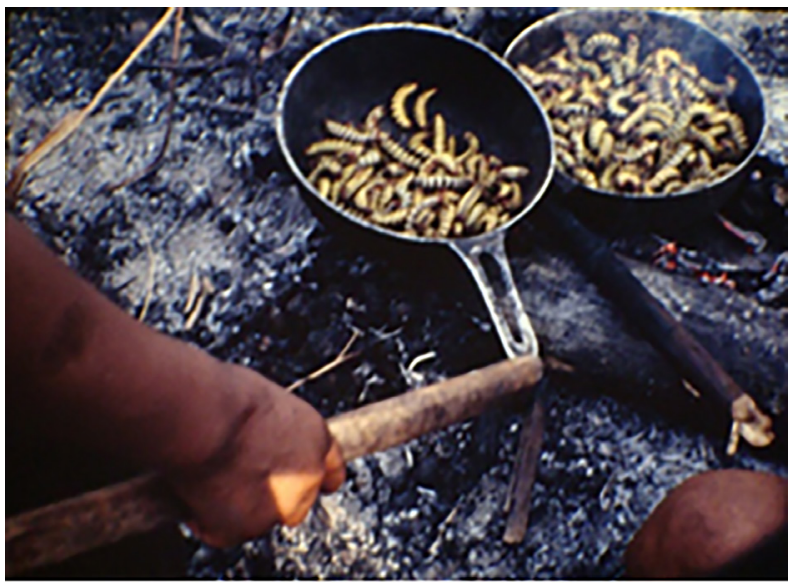

Figura 3. Witchu teip, un tipo de oruga comestible consumida entre los nukak en verano. Foto del autor.

Witchu teip, a type of caterpillar consumed by the nukak in the summer. Photo by the author.

Tabla 4. Comparativo de insectos usados por los pueblos nómadas.

Comparative of insects used by nomadic peoples.

\begin{tabular}{lccccccc}
\hline Pueblo indígena & Abejas & Hormigas & Avispas & Termitas & Larvas & Orugas & Abejorro \\
\hline nukak (a) & 43 & --- & 14 & --- & 2 & 16 & --- \\
\hline kakua o bará (b) & 8 & 12 & & 2 & 2 & & 1 \\
\hline hupda (c) & & & & $1 ?$ & $1 ?$ & $1 ?$ & \\
\hline juhup (d) & 2 & 1 & & & & & \\
\hline nadeb (e) & 6 & & & & & & \\
\hline Total & 59 & 13 & 14 & 3 & 5 & 17 & 1 \\
\hline
\end{tabular}

Fuentes: (a) Cabrera et al. 1999:295-299, (b) Silverwood-Cope 1990:51, (c) Reid 1979, (d) Mahecha et al. 2000; (e) Münzel 1969-1972:153. FUNAI.-PPTAL-GTZ 2008 
el hábito en el que se encuentran sus nidos, su tipo de nido y su nivel defensivo, tal como se muestra en la Tabla 5. Sobre ellas se han ofrecido breves descripciones y características particulares, siendo llamativo que algunas especies usadas por los nukak no son frecuentes e incluso para algunas de ellas se menciona que su miel o polen podría ser tóxicos (Nates y Cabrera 1999:64).

Las abejas usadas por los nukak como fuente de miel se aprecian en la Tabla 6. Al menos con siete de ellas se consumen sus larvas y de dos se reúne su cera. En cuanto a la cantidad de miel que aportan solo se tienen registros para ocho de las especies. Adicionalmente se aprecia que la variación estacional es importante, pues 12 de ellas se aprovechan en la estación seca, una en la lluviosa y las siete restantes todo el año. La especie más aprovechada por los nukak es llamada wuti be (Trigona corvina) y a pesar de su agresividad se aprovecha todo el año como revela la Tabla 7. Entre los nadeb su discernimiento sobre las abejas involucra cinco especies, de las que consideran la cantidad, el color y dulzura: "La abeja ' $r i$ ' produce miel negra muy dulce. $\mathrm{La}$ 'nabui', una miel muy abundante y mucho más fina que otras. La abeja 'ouchi' no produce miel que pueda ser aprovechada, pero reconocen su importancia. La miel más clara que conocen es

Tabla 5. Especies de abejas sin aguijón utilizadas por los nukak.

Stingless bee species used by nukak.

\begin{tabular}{|c|c|c|c|c|}
\hline Nombre nukak & Género y especie & Especie hábito & Tipo de nido & Defensa \\
\hline Buhnide & Trigona (Trigona) compressa Latreille & $\begin{array}{l}\text { Toichur ta' } \\
\text { Arit ta' }\end{array}$ & & \\
\hline Enat neun & Plebeia (plebeia) sp. & Duina (Lecythidaceae) & Interior & \\
\hline Itchiiwiawan & Partamona gr cupira Smith & Jiiwaina' ta' & Interior & \\
\hline Јіи butu & Cephalotrigona capitata capitata Smith & Kobota & Interior & Media \\
\hline Jiwun & Melipona gr fasciata & $\begin{array}{l}\text { Wedenide (Couma macrocarpa) } \\
\text { Duina (Lecythidaceae) }\end{array}$ & Interior & \\
\hline Kaiawo dawa & Trigona (Trigona) williana Friese & Juи & Interior & \\
\hline Kedari & Tetragona sp. & $\begin{array}{l}\text { Pujta' } \\
\text { Duina ta' (Lecythidaceae) }\end{array}$ & Interior, tubo a la entrada & Alta \\
\hline Kenoma & Melipona gr. fasciata & $\begin{array}{l}\text { Duina (Lecythidaceae) } \\
\text { Juruna (Socratea exhorrhiza) }\end{array}$ & Interior & \\
\hline Kibneun & Plebeia (Scaura) latitarsis Friese & & Dentro de nidos de comején & \\
\hline Manui bara & Melipona ebúrnea & Duina ta'(Lecythidaceae) & Interior & \\
\hline Manui jore & Melipona ebúrnea & $\begin{array}{l}\text { Duina ta'(Lecythidaceae) } \\
\text { Piripiri ta' (Inga sp) }\end{array}$ & Interior & \\
\hline Me tekere & Melipona rufiventris & $M e$ & Interior & \\
\hline Meu munu & Scaptotrigona cf. Postica Dalla Torre & $\begin{array}{l}\text { Hai' } \\
\text { Witchu be }\end{array}$ & $\begin{array}{l}\text { Interior (varios nidos en distintos lugares del } \\
\text { mismo árbol) }\end{array}$ & Media \\
\hline Patchumepude & Melipona interrupta grandis & & & \\
\hline Tojiwan & Scaptotrigona sp. 2 Della Torre & Kobota & Interior & \\
\hline $\mathrm{Tu}$ & Trigona (Trigona) dallatorreana Friese & & Exterior & Baja \\
\hline Tuu & Trigona (Trigona) pallens & & Dentro de nidos de comején & \\
\hline Wuti & Trigona (Trigona) spinipes & $\begin{array}{l}\text { Ut (Astrocaryum aculeatum) } \\
\text { Yam (Oenocarpus bataua })\end{array}$ & Exterior & Alta \\
\hline Wuti be' & Trigona (Trigona) corvina Cockerell & $\begin{array}{l}\text { Puyu (Bombacaceae) } \\
\text { Witchu } \\
\text { Wina' (Palmae) }\end{array}$ & Exterior & Alta \\
\hline Wuti butu & Trigona (Trigona) ferricauda & $\begin{array}{l}\text { Weina } \\
\text { Wina'(Palmae) }\end{array}$ & Exterior & Alta \\
\hline
\end{tabular}

Fuente: Cabrera et al. 1999 
Tabla 6. Uso de las abejas sin aguijón por los nukak.

\begin{tabular}{|c|c|c|c|c|c|}
\hline \multirow[b]{2}{*}{ Género y especie } & \multicolumn{4}{|c|}{ Uso y parte usada } & \multirow{2}{*}{$\begin{array}{c}\text { Estacionalidad } \\
\text { Periodo de } \\
\text { producción }\end{array}$} \\
\hline & $\begin{array}{l}\text { Consumo } \\
\text { de miel }\end{array}$ & $\begin{array}{c}\text { Cantidad de } \\
\text { miel }\end{array}$ & $\begin{array}{l}\text { Consumo } \\
\text { de larvas }\end{array}$ & $\begin{array}{l}\text { Recolección } \\
\text { de cera }\end{array}$ & \\
\hline Trigona (Trigona) compressa Latreille & + & & & & Estación seca \\
\hline Plebeia (plebeia) sp. & + & & & & Estación seca \\
\hline Partamona gr cupira Smith & + & & & & Estación seca \\
\hline Cephalotrigona capitata capitata Smith & + & & & & Estación seca \\
\hline Melipona gr fasciata & + & Término medio & & & Estación seca \\
\hline Trigona (Trigona) williana Friese & + & & + & & Estación seca \\
\hline Tetragona sp. & + & & + & & Todo el año \\
\hline Melipona ebúrnea & + & & + & & Todo el año \\
\hline Plebeia (Scaura) latitarsis Friese & + & Poca & & & Todo el año \\
\hline Melipona ebúrnea & + & & & & Estación seca \\
\hline Melipona ebúrnea & + & & & + & Todo el año \\
\hline Melipona rufiventris & + & Término medio & & & Estación seca \\
\hline Scaptotrigona cf. Postica Dalla Torre & + & Término medio & + & & Todo el año \\
\hline Melipona interrupta grandis & + & & & & Estación lluviosa \\
\hline Scaptotrigona sp. 2 Della Torre & + & & & & Estación seca \\
\hline Trigona (Trigona) dallatorreana Friese & + & Mucha & & & Estación seca \\
\hline Trigona (Trigona) pallens & + & & & & Estación seca \\
\hline Trigona (Trigona) spinipes & + & Poca & + & & Estación seca \\
\hline Trigona (Trigona) corvina Cockerell & + & Término medio & + & + & Todo el año \\
\hline Trigona (Trigona) ferricauda & + & Término medio & + & & Todo el año \\
\hline
\end{tabular}

Fuente: Cabrera et al. 1999.

producida por la 'nourou' o abeja jandaíra. Otra miel clara y más dulce es producida por la 'atube' o abeja tariana (FUNAI-PPTAL-GTZ 2008:43, mi traducción).

Entre los nukak la miel es colectada principalmente por los hombres y su consumo mayor es in situ. Se emplea para preparar aguamiel o endulzar bebidas de otros frutos. Algunas de estas bebidas pueden propiciar el embarazo o ser obsequiadas durante el cortejo (Cabrera et al. 1999; Franky 2011). Su consumo tiene ciertas restricciones, como la prohibición a la mujer de comerla los días siguientes a su parto pues pueden sufrir dolor de estómago, pudiendo hacerlo solo después de que su marido hace la curación soplándola. Así mismo, los hombres evitan el consumo en exceso pues se puede afectar la puntería en la cacería (Cabrera et al. 1999). Pero durante el embarazo también hay riesgos asociados por comer miel, como lo recuerda una mujer nukak llamada Chibma que contó como, durante el embarazo y lactancia, su padre le curó y autorizó a consumir miel de abejas como manui y cheujinwan. La curación de la última estaba además asociada al cuidado de sus dientes, pues esta abeja "cuando muerde es capaz de hacer cualquier cosa. A veces hace un hueco donde muerde. Va mordiendo y va haciendo hueco. Poco a poco va destruyendo los palos. Por eso tiene que rezarse, porque eso es capaz de tumbar los dientes" (Franky 2011:120).

De manera similar a los pueblos sedentarios la cera se emplea en elaboraciones materiales. Los nukak hacen flauta de hueso y zampoñas de bambú, de uso exclusivo masculino, los extremos de la flauta se taponan con cera pintada con achiote y ambos instrumentos se decoran con plumas y alas de apariencia metálica del cucarrón Eucroma gigantea; los cordeles para amarrar los tubos de la zampoña o carrizo, o las cuerdas transversales del chinchorro que elaboran las 
Tabla 7. Especies de abejas productoras de miel y sus periodos de recolección.

Honey-producing bee species and their harvesting periods.

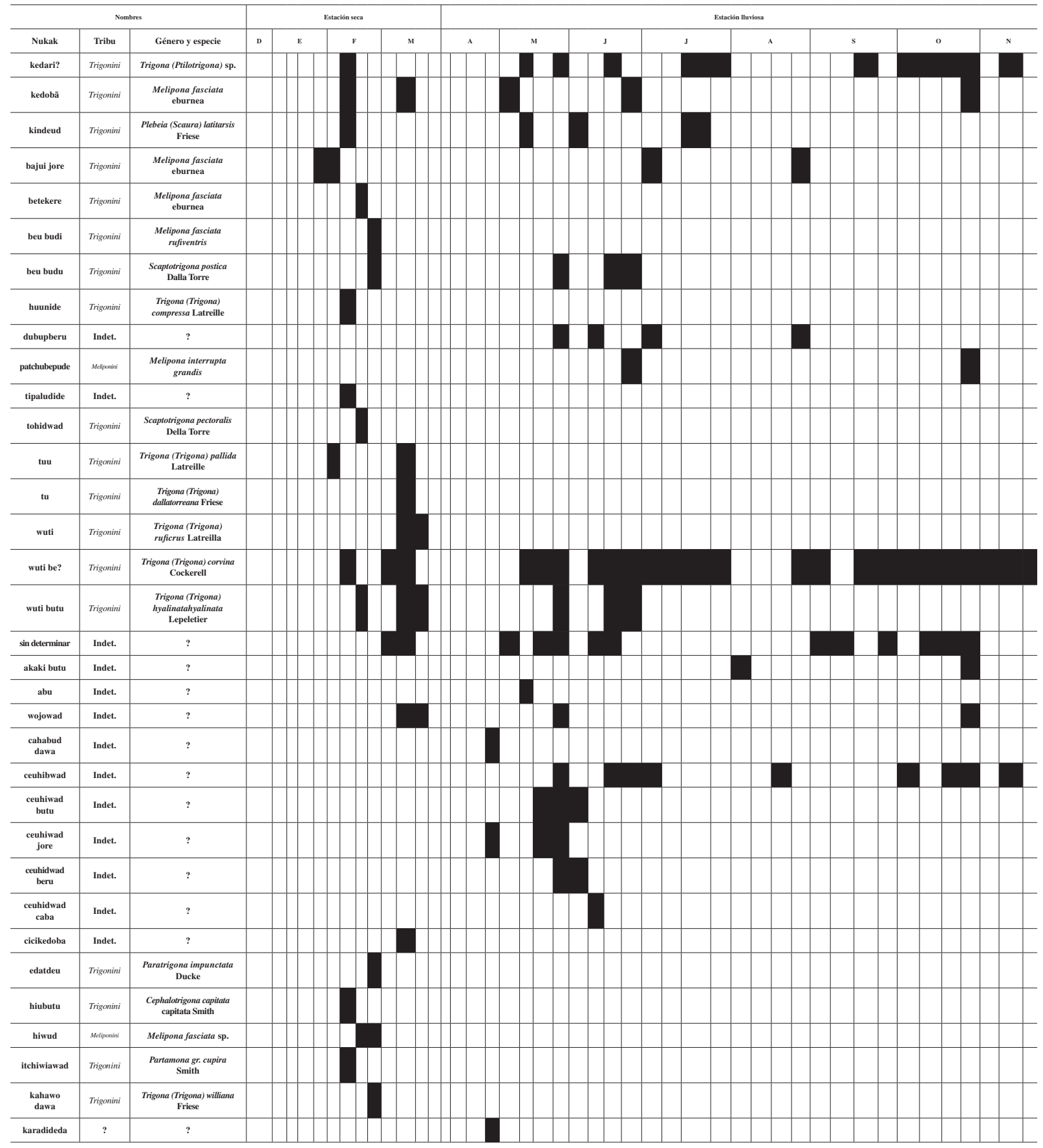


mujeres se impregnan con cera para que sujeten firmemente. Igualmente, la cerbatana se refuerza en el extremo de salida del dardo con un cordel que se enrolla y se cubre con cera para evitar que se rompa con los golpes, y a unos 30 centímetros del mismo extremo se hace la mira colocando un punto de cera. Las especies más usadas para esto son Melipona ebúrnea y Trigona corvina (Nates y Cabrera 1999:67) (Figuras 4, 5 y 6).

A los panales se accede por el mismo tronco que lo tiene, por otro árbol o se hace un andamio

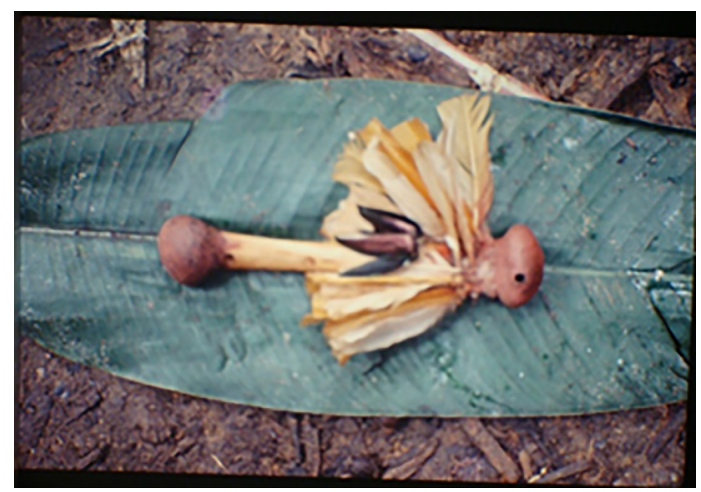

Figura 4. Flauta de hueso de venado con los extremos de cera pintados con achiote y decorada con plumas y alas de Euchroma gigantea. Foto del autor.

Deer bone flute with wax ends painted with annatto and decorated with feathers and wings of Euchroma gigantea. Photo by the author.
(Figura 7). Si la especie es agresiva, como Trigona corvina, T. spinipes, T. ferricauda y Tetragona sp., cuyas mandíbulas son fuertes, muerden y se enredan en el cabello antes de derribar el panal, se hace una antorcha con hojas secas de palma y se aproxima al panal para espantar los insectos, luego se desprende el panal con un palo que hace palanca (Figuras 8 y 9).

Otra especie llamada wijowan es muy agresiva y hace su nido en el interior de nidos de comején; a esta no se le pone fuego, sino que se desprende

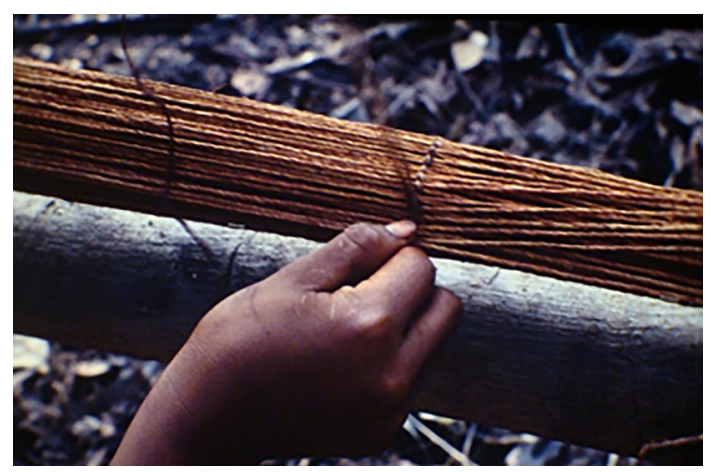

Figura 5. Detalle de las cuerdas transversales en la elaboración de chinchorros. Foto del autor.

Detail of transverse cords in the manufacturing of chinchorros. Photo by the author.

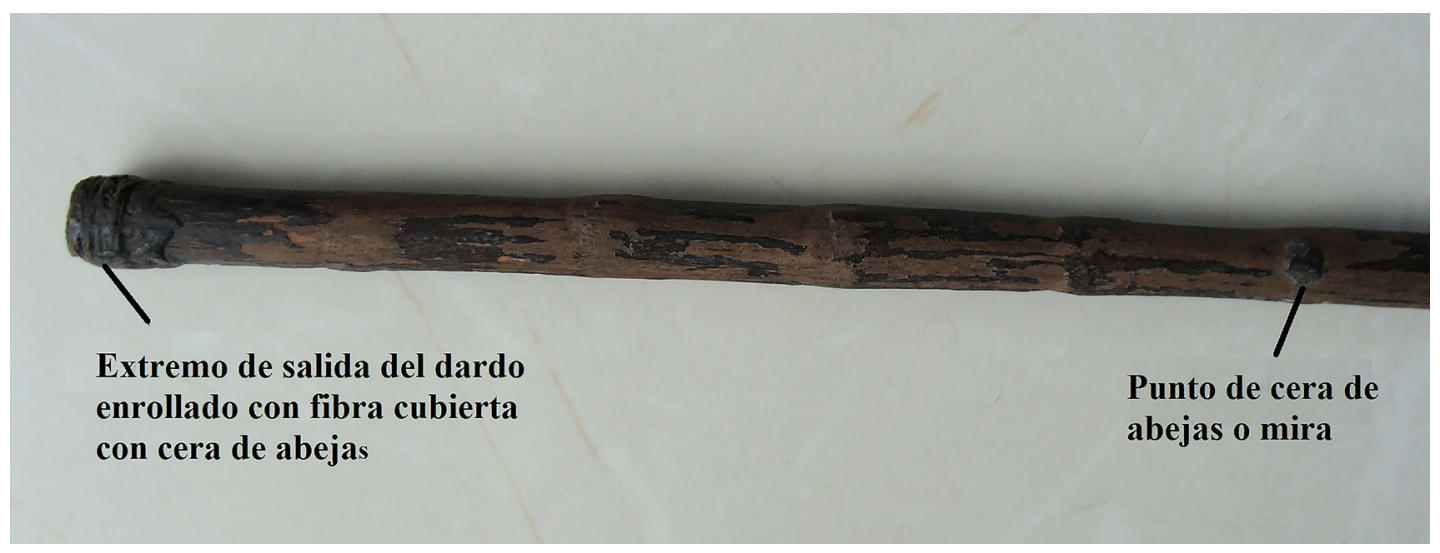

Figura 6. Detalles de la cerbatana nukak en la que se emplea cera de abejas. Foto del autor.

Details of a nukak blowgun with beeswax finishing. Photo by the author. 


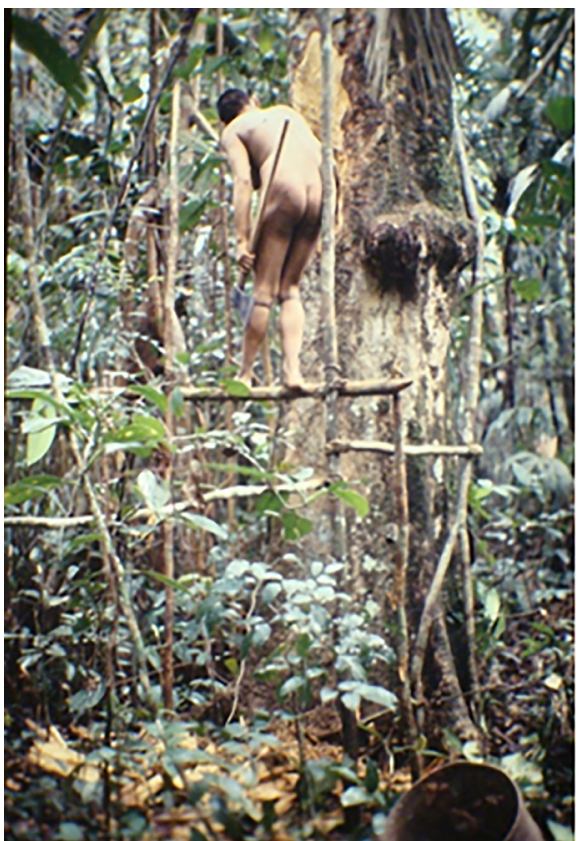

Figura 7. Kuriti extrayendo miel desde un andamio. Foto del autor.

Kuriti on a scaffold extracting honey. Photo by the author.

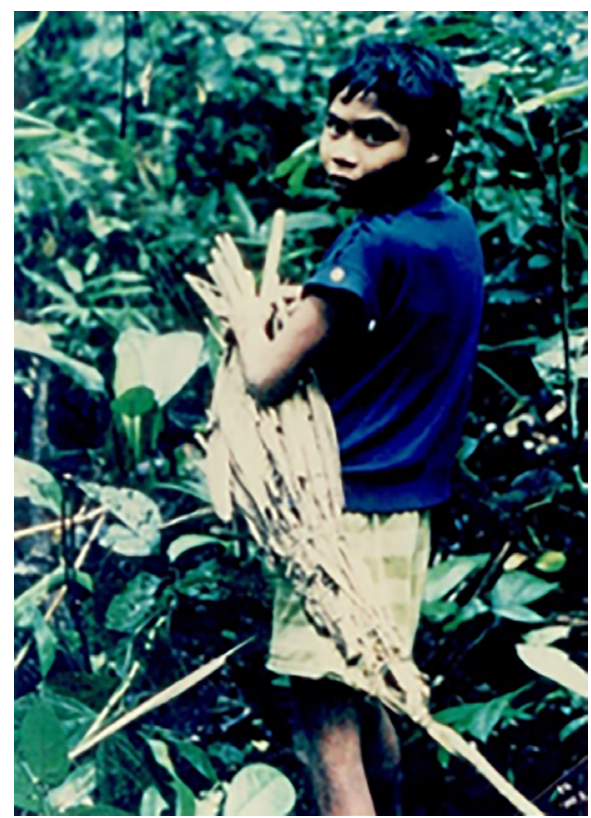

Figura 8. Daniel prepara la antorcha para poner humo bajo un panal. Foto del autor.

Daniel preparing a torch to smoke a beehive. Photo by the author.

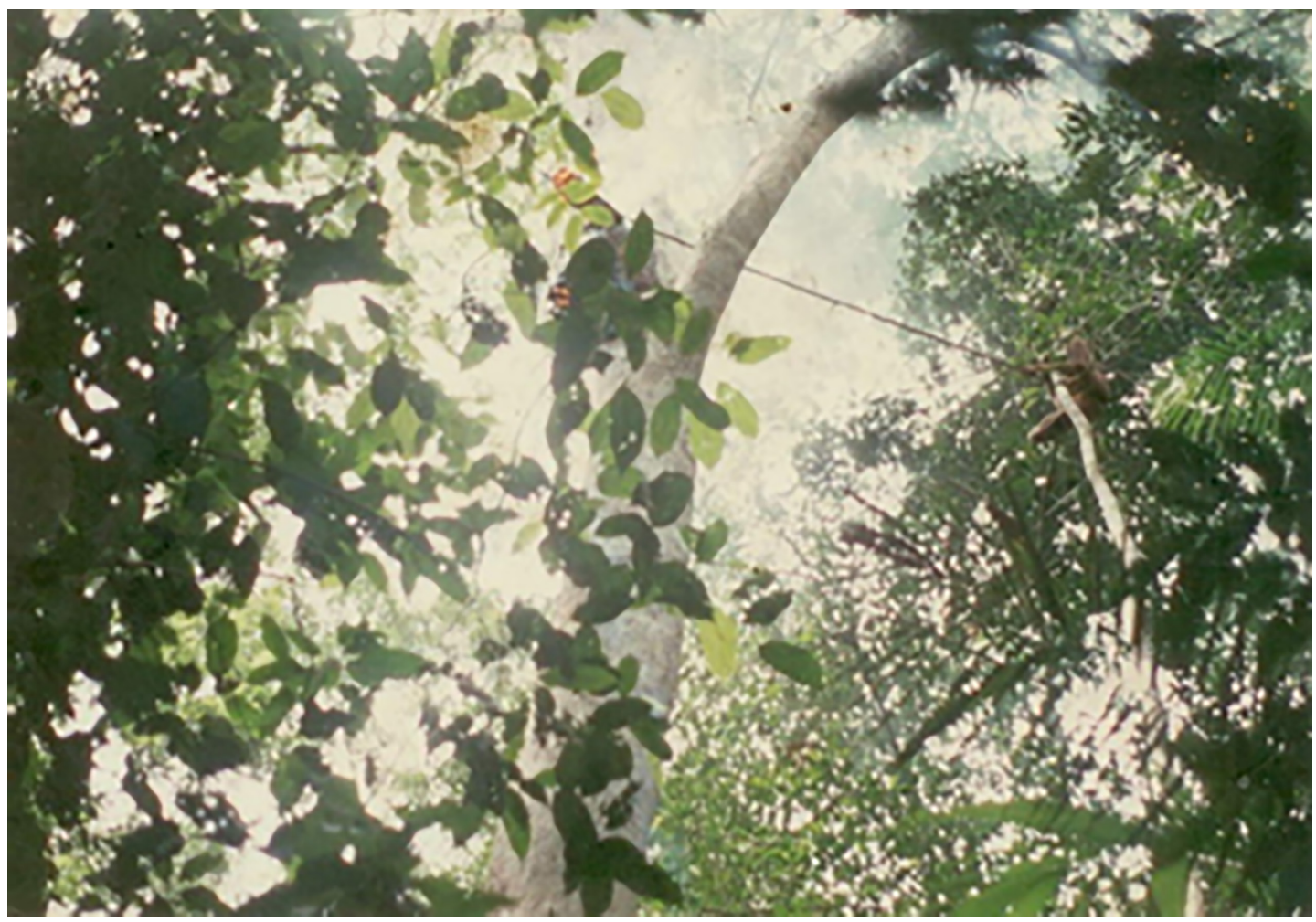

Figura 9. Empleo de la antorcha desde un árbol vecino al panal. Foto del autor. Using the torch from a tree next to the honeycomb. 
el mismo haciendo palanca con un palo, se busca el nido de abejas en su interior se extrae y sacude y se corre alejándose del lugar rápidamente (Nates y Cabrera 1999:68). La recolección de miel de los nukak es esencialmente destructiva, pues los nidos se dañan y quedan en malas condiciones siendo difícil que sobrevivan al ataque de depredadores o parásitos, como se aprecia en la Figura 10. Empero, por el lugar de la actividad, en la oferta global de alimentos es posible que no se vean tan afectadas (Nates y Cabrera 1999:68). Circunstancia similar descrita para los nadeb entre quienes "no fue identificada ninguna forma de manejo, solamente la recolección directa del producto (FUNAIPPTAL-GTZ 2008:43, mi traducción).

En cuanto al mojojoy los nukak lo consumen en todos los estados de desarrollo, las larvas se pueden comer crudas o asadas, en tanto que el insecto adulto se come vivo y sus huéspedes más comunes son el seje o milpeso (Oenocarpus bataua), el moriche o canangucha (Mauritia flexuosa) y la palma real o inaya (Attalea maripa), como se aprecia en la Figura 11. El insecto adulto también es capturado por los niños que le atan una fina cuerda tras su cabeza y le hacen volar dando vueltas. El valor nutricional de este recurso es elevado y se le compara al de un

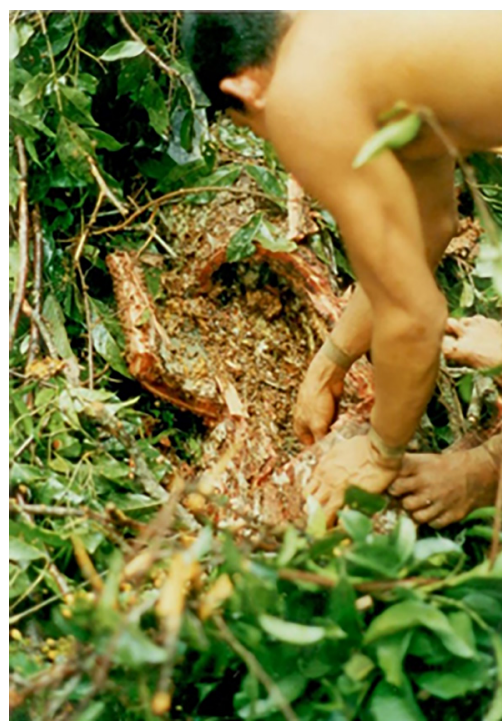

Figura 10. Keeje explora el nido de abejas, que tras la colecta queda muy destruido. Foto del autor.

Keeje explore the honeycomb, which after the collection is very destroyed. embutido de cerdo, en tanto el de algunas orugas se asemeja al hígado de gallina (Dufour 1987:389).

La Tabla 8 muestra que el nomadismo nukak incluye un $16 \%$ del total de sus actividades ligadas a los insectos $(9,46 \%)$, para recolección de miel y $(5,61 \%)$ recolección de insectos; en tanto que entre los semisedentarios juhup el total de las mismas actividades es 3,56\% distribuidas en recolección de insectos $(3,06 \%)$ y recolección de miel $(0,5 \%)$. Las cifras son un reflejo claro de qué tanto recorren el bosque los dos pueblos.

Así mismo la Tabla 9 permite observar desde una óptica cuantitativa la distribución de su importancia de acuerdo con el orden de los insectos. Son los himenópteros (abejas, avispas, hormigas) los que más se aprovechan en la zona. Aunque la diferencia es notoria con relación al total de abejas, no lo es en cuanto a las avispas y hormigas. Los nómadas aprovechan casi tres veces más lepidópteros (orugas) que los sedentarios. Pero estos, a su vez, aprovechan tres veces más los Isópteros (termitas) y los Coleópteros (larvas e insecto adulto). El aprovechamiento mayor de las abejas es un claro indicador del hábitat hacia el cual los nómadas inclinan la consecución de los alimentos, es decir el bosque. En las Figuras 12 y 13 se puede contrastar el uso estacional de recursos entre sedentarios y nómadas.

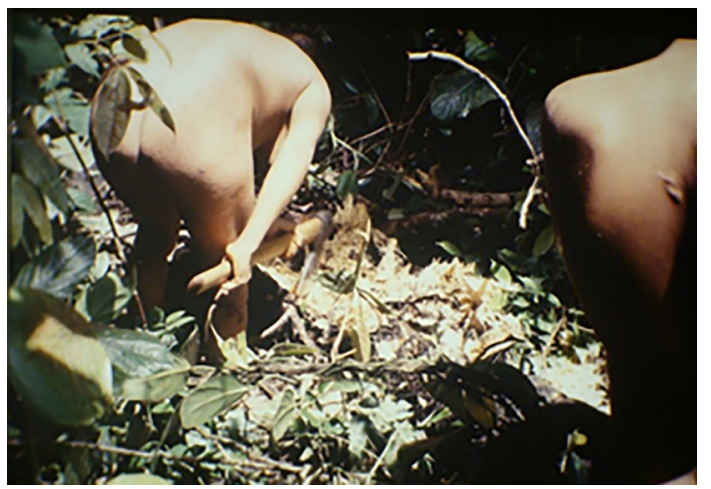

Figura 11. Mujeres nukak colectando mojojoy. Foto del autor. Nukak women collecting mojojoy. Photograph by the author 
Tabla 8. Distribución de las actividades de subsistencia entre los nukak y los juhup.

Distribution of subsistence activities between nukak and juhup.

\begin{tabular}{lccc}
\hline \multicolumn{1}{c}{ Nukak } & & & Juhup \\
\hline \multicolumn{1}{c}{ Actividad } & $\begin{array}{c}\text { Porcentaje } \\
\%\end{array}$ & Actividad & $\begin{array}{c}\text { Porcentaje } \\
\%\end{array}$ \\
\hline Recolección de vegetales & 32,49 & Horticultura & 31,30 \\
\hline Caza & 21,59 & Pesca & 50,0 \\
\hline Pesca & 18,22 & Caza & 7,88 \\
\hline Horticultura & 12,61 & Recolección de vegetales & 9,68 \\
\hline Recolección de miel & 9,46 & Recolección de insectos & 0,78 \\
\hline Recolección de insectos & 5,61 & Recolección de miel & 0,33 \\
\hline Fuente: Mahecha et al. 2000. & & &
\end{tabular}

Tabla 9. Comparativo de uso de insectos entre pueblos sedentarios y nómadas del Vaupés.

Comparative of insect use between sedentary and nomadic peoples of Vaupés.

\begin{tabular}{|c|c|c|c|c|}
\hline \multirow[b]{2}{*}{ Orden } & \multicolumn{2}{|c|}{ Sedentarios ( 9 pueblos) } & \multicolumn{2}{|c|}{ Nómadas (5 pueblos) } \\
\hline & $\begin{array}{l}\text { Número de } \\
\text { especies }\end{array}$ & $\underset{\%}{\text { Porcentaje }}$ & $\begin{array}{l}\text { Número de } \\
\text { especies }\end{array}$ & $\begin{array}{c}\text { Porcentaje } \\
\%\end{array}$ \\
\hline Himenópteros (abejas, avispas, hormigas) & $\begin{array}{c}83 \\
(18,14,51)\end{array}$ & 56.4 & $\begin{array}{c}85 \\
(58,14,13)\end{array}$ & 73,2 \\
\hline Lepidópteros (orugas) & 6 & 4 & 17 & 14,6 \\
\hline Isópteros (termitas) & 11 & 7,4 & 3 & 2,5 \\
\hline Coleópteros (larvas e insecto adulto) & 15 & 10,2 & 5 & 4,3 \\
\hline Odonatos & 1 & 0,6 & & \\
\hline Hemípteros (cigarras, fulgomorfos, saltahojas, cochinillas, chinches) & 7 & 4,7 & & \\
\hline Ortópteros (saltamontes, langostas, grillos) & 4 & 2.7 & & \\
\hline Abejorro & & & 1 & 0,8 \\
\hline Larvas & 14 & 9,5 & 5 & 4,3 \\
\hline Indeterminados & 6 & 4 & & \\
\hline Total de insectos & 147 & & 116 & \\
\hline
\end{tabular}

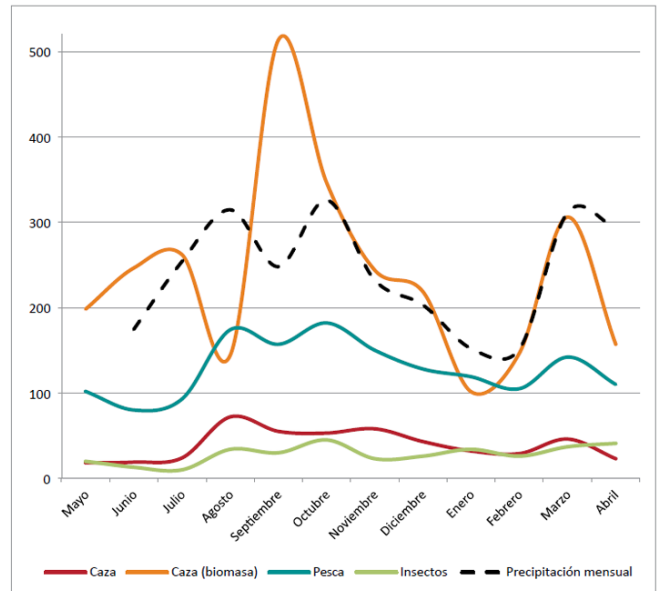

Figura 3.7 Estacionalidad del uso de fauna de consumo (Cacería, pesca e insectos) en las comunidades de Bella Vista y Puerto Loro

(1 de mayo 2013 a 30 de abril 2014), comparado con los valores mensuales de precipitación medidos localmente (Junio 2013 - Abril 2014). Nota: Para el mes de mayo de 2013 no se cuenta con datos de precipitación.

Figura 12. Estacionalidad en la zona del Río Tiquié (caza, pesca e insectos). Tomado de Osorno et al. 2014:69. Seasonality in the Tiquié river area (hunting, fishing and insects). Taken from Osorio et al. 2014:69. 


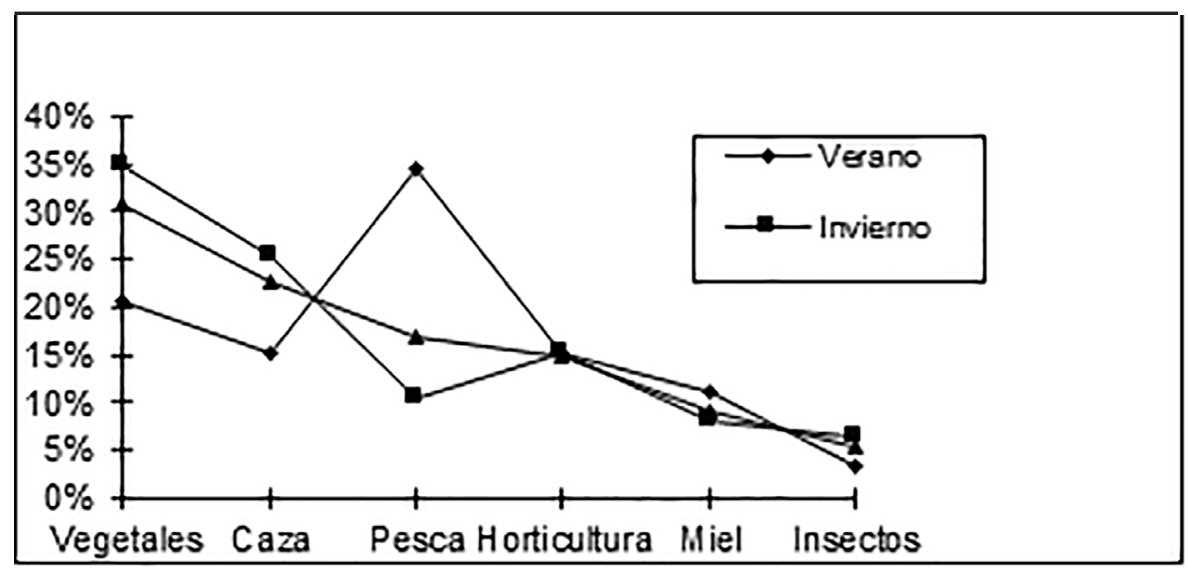

Figura 13. Estacionalidad de actividades de consecución de alimentos entre los nómadas nukak. Tomado de Cabrera et al. 1999:304.

Seasonality of food procurement activities among Nukak nomads. Taken from Cabrera et al. 1999:304.

\section{A Manera de Conclusión}

El análisis de los datos de los nukak y juhup, que fueron recogidos en trabajos de campo directos con la misma metodología, permite apreciar un matiz en el orden que ocupan las actividades de consecución de alimentos entre dos pueblos de tradición nómada. Los registros etnográficos sobre sedentarios y nómadas del área de este estudio permiten observar que hay un espectro importante de insectos. Pero la diferencia entre la cantidad e intensidad es notoria. Los pueblos sedentarios enfatizan el consumo de un número bajo de especies de hormigas, termitas y larvas. Los nómadas como los nukak, en tanto, tienen un elevado número de especies que aprovechan, especialmente abejas. Tanto nómadas como sedentarios aprovechan los insectos según la estacionalidad de su oferta, tal y como se aprecia en los datos de los sedentarios bara y tuyuka del Río Tiquié no hay mucha variación en el aprovechamiento de insectos; con relación a los nómadas nukak se revela que en verano hay un ligero incremento en la búsqueda de miel y que con respecto a los insectos su captura disminuye un poco en verano.

Los insectos son un elemento complementario a la dieta de ambos grupos de población, que aún se mantiene localmente. El avance de la relación con sectores de la sociedad nacional puede llevar a que el consumo entre en decadencia o caiga en el llamado consumo oculto, en el que no solo se privilegian alimentos de otro origen, atendiendo el reiterado discurso de los blancos que subvalora esta práctica, sino que se generan nociones de vergüenza interiorizadas sobre lo propio, como señala otro investigador para grupos de otra región amazónica (Calle 2000:157). Comer no es el simple acto de la ingesta, aún con los alimentos como los insectos que son una pequeña parte del espectro nutricional entre los indígenas; hay asociaciones simbólicas que los vinculan al ciclo vital de los individuos, a la estacionalidad de la oferta de recursos, al proceso de curación o tratamiento de la enfermedad, al intercambio entre grupos o en el cortejo y la ejecución de actividades cotidianas. Adicionalmente, los conocimientos sobre sus hábitos, que son muy valiosos, demuestran lo diversa que es la humanidad y el conocimiento de la naturaleza; saberes que no deben desaparecer, pero que están amenazados por la sustitución de los hábitos alimenticios, el avance de la deforestación, la prospección minera, el desarrollo de infraestructura o cualquier otra actividad que destruye sus hábitats.

Agradecimientos: Agradezco a los evaluadores, cuyos comentarios permitieron precisar y clarificar los contenidos del texto. 


\section{Referencias Citadas}

Arhem, K. 1991. Los Makuna en la historia cultural del Amazonas. Boletín Museo del Oro 30:83-95.

Arhem, K. 1981. Makuna Social Organization. A Study in Descent, Alliance and the Formation of Corporate Groups in the North-Western Amazon. Acta Universitatis Upsalensis, Uppsala.

Arhem, K., L. Cayón, G. Angulo y M. García 2004. Etnografía Makuna. Tradiciones, Relatos y Saberes de la Gente de Agua. Instituto Colombiano de Antropología e Historia, Acta Universitatis Gothoburgensis, Bogotá.

Athias, R. 2006. Os Hup'däh. En A Língua dos Hup'däh do Alto Rio Negro. Dicionário e Guia de Conversação, editado por H. Ramírez, pp. 9-28. Associação Saúde Sem Límites, São Paulo.

Balick, M.J. 1986. Systematics and economics botany of the Oenocarpus jessenia (Palmae) complex. Advances in Economic Botany 3:1-140.

Beckerman, S. 1982 [1979]. La abundancia de proteína en la Amazonia: una respuesta a Gross. Amazonia Peruana 3 (6):91-125.

Cabrera, G. 2005. El sedentarismo de los pueblos Makú y el empobrecimiento de la biodiversidad. Una visión comparada entre los Nukak y los Juhup de la amazonia colombiana. Astrolabio 4 (2):61-72.

Cabrera, G. 2010. Un siglo de investigaciones sobre los Makú. En Viviendo en el Bosque. Un Siglo de Investigaciones sobre los Makú del Noroeste Amazónico, editado por G. Cabrera, pp. 17-27. Universidad Nacional de Colombia, Medellín.

Cabrera, G. y G. Nates-Parra 1999. Uso de las abejas por comunidades indígenas: los Nukak y las abejas sin aguijón. Programa, resúmenes y memorias III Reunión de la IUSSI Bolivariana, editado por G. Nates-Parra, pp. 59-70. Fondo FEN Colombia. Departamento de Biología, Universidad Nacional de Colombia, Bogotá.

Cabrera, G., C.E. Franky y D. Mahecha 1999. Los Nukak: Nómadas de la Amazonia Colombiana. Universidad Nacional de Colombia, Programa COAMA, Gobierno de Dinamarca, Bogotá.

Calle, H. 2000. Enfermedades, epidemias y prácticas curativas entre los Murui-Muinanes de los ríos Cará-Paraná e Igará-Paraná en el Putumayo. En Amazonia Colombiana: Enfermedades y Epidemias. Un estudio de Bioantropología Histórica, editado por A.J. Gómez-López. H.A. SotomayorTribín y A.C. Lesmes-Patiño, pp. 145-185. Ministerio de Cultura, Bogotá.

Cartay, R. 2018. Entre el asombro y el asco: el consumo de insectos en la cuenca amazónica. El caso del Rhynchophorus palmarum (Coleoptera curculionidae). Revista Colombiana de Antropología 54 (2):143-169.

Correa, F. 1996. Por el Camino de la Anaconda Remedio, Dinámica de la Organización Social entre los Taiwano del Vaupés. Universidad Nacional de Colombia, Bogotá.

Chernela, J.M. 1983. The Wanano Indians of the Brazilian Amazon. University of Texas Press, Austin.

Dufour, D.L., B.A. Piperata, R.S. Murrieta, W.M. Wilson y D. Williams 2016. Amazonian foods and implications for human biology. Annals of Human Biology 43 (3):330-348,
Dufour, D.L. 1987. Insect as food. A case study from the Northwest Amazon. American Anthropologist 89 (2):383397.

Dufour, D.L. 1984-1985. Flujo de energía a través de los hogares Tatuyo: análisis preliminar. Revista Colombiana de Antropología 25:235-262.

Epps, P. 2008. A Grammar of Hup. Mouton de Gruyter, New York.

FAO 2013. Edible Insects: Future Prospects for Food and Feed Security. FAO, Roma.

Fernández, F. 1999. Sistemática y filogenia de los insectos sociales (HYMENOPTERA) en la región neotropical. Programa, resúmenes y memorias III Reunión de la IUSSI Bolivariana, editado por G. Nates Parra, pp. 31-39. Fondo FEN Colombia. Departamento de Biología, Universidad Nacional de Colombia, Bogotá.

Franky, C.E. 2011. 'Acompañarnos Contentos con la Familia': Unidad, Diferencia y Conflicto entre los Nükak (Amazonia Colombiana). Wageningen University, Wageningen.

Freire, G. y S. Zent 2007. Los Piaroa (Huottuja/De' aruhua). En Salud indígena en Venezuela, editado por G. Freire y A. Tillett, Vol I, pp. 133-207. Ministerio del Poder Popular para la Salud, Instituto Caribe de Antropología y Sociología, Fundación La Salle, Caracas.

FUNAI-PPTAL-GTZ 2008. Levantamento Etnoecológico Maku: Terra Indígena Paraná do Boá-Boá. Fundação Nacional do Indio, Projeto Integrado de Proteção as Populações e Terras Indígenas da Amazônia Legal, Gesellschaft fur Technische Zusammenarbeit, Brasilia.

Goldman, I. 1968. Los Cubeo. Indios del Noroeste del Amazonas. Instituto Indigenista Interamericano, México DF.

Gross, D. 1982a. Consumo proteínico y desarrollo cultural en la cuenca amazónica. Amazonia Peruana 3 (6): 59-90.

Gross, D. 1982b. Proteína y cultura en la Amazonia: una segunda revisión. Amazonia Peruana 3 (6):127-143.

Hill, J.D. 1986. Representaciones musicales como estructuras adaptativas: la música de los bailes ceremoniales de los Arawakos Wakuénai. Montalbán 17:67-101.

Hill, J.D. y M. Oliver 2007. Los Curripaco (Kurrim, Wakuénai. En Salud Indígena en Venezuela, editado por G. Freire y A. Tillett, Vol I, pp. 19-75. Ministerio del Poder Popular para la Salud, Instituto Caribe de Antropología y Sociología, Fundación La Salle, Caracas.

Hugh-Jones, S. 2013. La Palma y las Pléyades. Iniciación y Cosmología en la Amazonia Noroccidental. Universidad Central, Bogotá.

Jackson, J.E. 1983. Identidad lingüística de los indios colombianos del Vaupés. En Lenguaje y Sociedad, pp. 379397. Centro de traducciones de Univalle, Cali.

Jara, F. 1996. La miel y el aguijón. Taxonomía zoológica y etnobiología como elementos en la definición de las nociones de genero entre los Andoke (Amazonia colombiana). Journal de la Societé des Américanistes 82:209-258.

Lizot, J. 2007. Los Yanomami (Yãnomãmi). En Salud indígena en Venezuela, editado por G. Freire y A. Tillett, Vol. I, pp. 263-323. Ministerio del Poder Popular para la Salud, Instituto 
Caribe de Antropología y Sociología, Fundación La Salle, Caracas.

Mahecha, D., C.E. Franky y G. Cabrera 2000. Nukak, Kakua, Juhup y Hupdu (Makú). Cazadores nómadas de la Amazonia colombiana. En Geografía Humana de Colombia. Tomo VII. Vol. II, editado por F. Correa Rubio, pp. 129-211. Instituto Colombiano de Antropología e Historia, Bogotá.

Martins, V. 2005. Reconstrução Fonológica do Protomaku Oriental. Tesis Doctoral, LOT Dissertation Series No. 104, Vrije Univesiteit (Amsterdam), Utrecht.

Milton, K. 1984. Protein and carbohydrate resources of the Maku Indians of Northwestern Amazonia. American Anthropologist 86:7-27.

Münzel, M. 1969-1972. Notas preliminares sôbre os kaborí (Makú entre o rio negro e o Japurá). Revista de Antropología 17/20 (1):137-181.

Nates-Parra, G. 1999. Situación actual de la sistemática de abejas (HYMENOPTERA:APOIDEA). Programa, resúmenes y memorias III Reunión de la IUSSI Bolivariana, editado por Guiomar Nates-Parra, pp. 49-55. Fondo FEN Colombia. Departamento de Biología, Universidad Nacional de Colombia, Bogotá.

Oliveira, F.F. De, B.T.J. Richers, J.R. Da Silva. R.C. Farias y T.A. De L. Matos 2013. Guia Ilustrado das Abelhas "Sem-Ferrão" das Reservas Amanã e Mamirauá, Brasil (Hymenoptera, Apidae, Meliponini). Instituto de Desenvolvimento Sustentável Mamirauá, Tefé.

Ortiz, R. 1994. Uso Conocimiento y Manejo de Algunos Recursos Naturales en el Mundo Yucuna. Ediciones AbyaYala, Quito.

Osorno, M., N. Atuesta, L.F. Jaramillo, S. Sua, A. Barona y N. Roncancio 2014. La Despensa del Tiquié. Diagnóstico y Manejo Comunitario de la Fauna de Consumo en la Guyana Colombiana. Instituto Amazónico de Investigaciones Científicas, Bogotá.

Paoletti, M.G. y D.L. Dufour 2000. Edible Invertebrates among Amazonian Indians: A Critical Review of Disappearing Knowledge. Environment Development and Sustainability 2 (3): 195-225
Ramirez, H. 2001. Ye 'Pâ-Masa Te Niisehétisehe: a vida dos Ye 'Pâ-Masa. Editora da Universidade do Amazonas, Manaus.

Reichel-Dolmatoff, G. 1986. Desana. Simbolismo de los Indios Tucano del Vaupés. Procultura, Bogotá.

Reichel-Dolmatoff, G. 1996. The Forest Within. The WorldView of the Tucano Amazonian Indians. Themis Books, Devon.

Reichel-Dolmatoff, G. 1997. Chamanes de la selva pluvial. Ensayos sobre los indios Tucano del Noroeste Amazónico. Themis Books, Devon.

Reid, H. 1979. Some Aspects of Movement, Growth and Change among the Hupda Maku Indians of Brazil. Thesis Ph.D., University of Cambridge, Faculty of Archaeology and Anthropology, Cambridge.

Ross, E.B. 1978. Food taboos, diet, and hunting strategy: The adaptation to animals in Amazonian cultural ecology. Current Anthropology 19:1-36.

Silverwood-Cope, P.L. 1990. Os Makú. Povo Caçador do Noreste da Amazônia. Editora Universidade de Brasilia, Brasilia.

Sorensen, A.P. 1967. Multilingualism in the Northwest Amazon. American Anthropologist 69 (6):670-684.

Sotomayor-Tribín, H.A., D. Mahecha, C.E. Franky, G. Cabrera y M.L. Torres-Leguízamo 1998. La nutrición de los Nukak una sociedad amazónica en proceso de contacto. Maguaré 13:117-142.

Vickers, W. 1983. The territorial dimensions of Siona Secoya and Encabellado adaptation. En Adaptive Responses of Native Amazonians, editado por R. Hames y W. Vickers, pp. 451-477. Academic Pres, New York

Wright, R.M. 1983. Lucha y supervivencia en el noroeste de la Amazonia. América indígena 43 (3):537-554.

Zent, E.L. y S. Zent 2007. Los Jodi (Hoti). En Salud Indígena en Venezuela, editado por G. Freire y A. Tillett, Vol. I, pp. 77-131. Ministerio del Poder Popular para la Salud, Instituto Caribe de Antropología y Sociología, Fundación La Salle, Caracas. 
